\title{
Mapping the Impact of Social Media for Innovation: The role of social media in explaining innovation performance in the PDMA Comparative Performance Assessment Study
}

\author{
Deborah L. Roberts, Nottingham University* \\ Frank T. Piller, RWTH Aachen University \\ Dirk Lüttgens, RWTH Aachen University
}

\begin{abstract}
*Address correspondence to: Deborah L. Roberts, Nottingham University Business School, North Building Jubilee Campus, Wollaton Road, Nottingham NG8 1BB, UK. E-mail: deborah.roberts@ nottingham.ac.uk. Tel: +44(0)115 8466562

Contact information of remaining authors: RWTH Aachen University, School of Business \& Economics, TIME Research Area, Templergraben 55, 52056 Aachen, Germany. E-mail: piller@time.rwth-aachen.de, lüttgens@time.rwth-aachen.de
\end{abstract}

\section{Biographical Sketches}

Dr. Deborah L. Roberts is an Associate Professor at the University of Nottingham Business School, where she specializes in new product and service development. Her research interests include the use of social media for innovation, co-creation of value, market learning for innovation, and technology visioning for radical innovation. Publications may be found in MIT Sloan Management Review, Journal of Product Innovation Management, R\&D Management, European Journal of Marketing and the International Journal of Market Research. Deborah obtained a PhD from Cranfield University School of Management. Prior to this, she held a number of senior appointments in marketing and NPD within retail, FMCG, and leisure sectors. During this time she gained membership of the Chartered Institute of Marketing and an MBA from Durham University Business School.

Dr. Frank T. Piller is a professor for management at RWTH Aachen University, where he heads the Technology \& Innovation Management Group and is the academic director of the EMBA program. His research interests include open and user innovation, mass customization, managing disruptive change, and implications of new information technologies for new product development. Frank's research has been published in Academy of Management Perspectives, Journal of Product Innovation Management, R\&D Management, Journal of Operations Management, MIT Sloan Management Review, amongst others. He obtained a Ph.D. from the University of Wurzburg and worked at TU Munich, HKUST, and MIT Sloan School of Management.

Dr. Dirk Lüttgens is an assistant professor in the Research Area TIME (Technology, Innovation, Marketing, and Entrepreneurship) at RWTH Aachen University and is a visiting scholar at the Haas School of Business, University of Berkeley, CA. His research focuses on open innovation, business model innovation, and the implications of the current digital transformation on firms. Dirk obtained a Ph.D. in innovation management from RWTH Aachen University. He also worked at the University of Applied Sciences in Luzern, Switzerland, and has been a lecturer in several executive programs.

Acknowledgements: The authors are grateful for the advice and comments by the editors and three anonymous reviewers. The authors acknowledge the input from Nina Jost to an earlier version of this article and thank the participants of the RWTH Innovation Research Seminar and at the PDMA Research Forum for their input and ideas. Funding for this research from a Nottingham University Business School paper development fund is gratefully acknowledged. 


\begin{abstract}
Social media (SM) allow users to easily create, edit, or share content. The vast numbers of individuals that converge around sites like LinkedIn, Facebook, or Twitter embody a rich source of external knowledge that could be utilized for new product development (NPD). Complementing other channels for open innovation, SM can provide access to novel information about customer needs and technological solutions unknown to the firm. Anecdotal evidence suggests that there are considerable benefits from using SM during an innovation project, but empirical evidence is scare. Contributing to the perspective of openness in search, a number of hypotheses propose how SM as a new channel for open innovation can contribute to firm performance. This model is tested using data from the PDMA Comparative Performance Assessment Study (CPAS), identifying factors influencing the relationship between SM and NPD performance. The findings indicate that utilizing information from SM channels can lead to higher performance, but that this link is influenced by the formalization of a firm's NPD process. This study also finds that the ability of a firm to benefit from external search in SM strongly depends upon complementary internal processes when organizing and conducting this activity. Furthermore, managers have to take care when utilizing information from SM channels in radical projects, as for this kind of projects only a weak significant performance contribution of SM could be found.
\end{abstract}

\title{
Practitioner Points
}

- Utilizing input from social media (SM) channels can increase innovation project performance, as firms get access to novel market insights and innovative technical solutions.

- To benefit from SM for innovation, firms need to acquire new skills, procedures, and competences to interpret and evaluate the information derived from these sources.

- Exploring SM without having these capabilities can even reduce performance.

- Firms hence need to make SM part of their open innovation strategy.

\section{Introduction}

In a global marketplace that is becoming increasingly data rich and complex, organizations are searching for new ways to improve their innovation performance. One such way is to adopt an open innovation (OI) modus operandi (Chesbrough, 2003). While OI has several theoretical foundations and conceptualization (Randhawa et al., 2016), a large stream of the OI literature focuses on strategies of firms to increase the breadth and depth of their search activities to acquire relevant external knowledge (e.g., Laursen and Salter, 2006; Dahlander and Gann, 2010; Afuah and Tucci, 2012). There is widespread acceptance that incorporating knowledge from a broad scope of external sources into the new product development (NPD) 
process leads to higher innovation performance (Foss et al., 2011; Nelson and Winter, 1982). However, recently new opportunities to collaboratively create and share knowledge have emerged, facilitated by a novel class of information technologies, commonly referred to as social media (Kane et al., 2014).

Social media (SM) is a broad term, comprising a variety of internet-based technologies and social networking services. Within just one decade, popular SM sites such as LinkedIn, Facebook, or Twitter have been embraced by billions of users across the globe, achieving unprecedented reach and penetration. The vast number of individuals and communities that converge around these sites embody a large and rich source of external knowledge. In this study the term SM refers to "a group of internet-based technologies that allows users to easily create, edit, evaluate, and/or link to content or to other creators of content" (Majchrzak et al., 2013: 38). As firms have recognized the potential applications and benefits of using SM for commercial purposes, forecasts for spending on SM initiatives are set to increase. With regard to NPD, it has been suggested that SM will broadly influence the innovation process. Users can share experiences, needs, and problems with current products, but also can take part in a range of firm-initiated activities from posting comments on product ideas to participating in co-creation activities such as designing new products (Kietzmann et al., 2011; Roberts and Piller, 2016). Users and the SM communities they form are hence recognized as sources of inspiration, and as creative sources in their own right (Kozinets, 2002).

The most recent PDMA Comparative Performance Assessment Study (CPAS) study indicated that the best performing firms are using a variety of IT tools to speed new products to market, and higher performing firms used more SM than lower performing firms (Markham and Lee, 2013). However, the adoption of SM tools for NPD is still evolving, and it still is unclear how these new technologies will impact NPD performance (Kane et al., 2014). To date, effectively utilizing SM for NPD has proven challenging and firms have demonstrated mainly lackluster 
results (Culnan et al., 2010; Marion et al., 2014; Roberts and Candi, 2014).Given the speed in which users have embraced SM, this is an area ripe for research. Thus, the purpose of this study is to enrich our understanding of the role of SM as a novel search channel for (open) innovation.

This study contributes to the literature in several ways. First, it responds to recent calls in this journal for a more integrated perspective of open innovation research (Antons et al., 2015; Randhawa et al. 2016). Prior research has predominantly studied how a focal firm can leverage professional external partners through formalized (contractual) relationships across an industrial value network. This study, by contrast, adopts the entire network of external stakeholders and potential information sources as the level of analysis and hence explores networks characterized by unstructured knowledge sources and informal relationships.

Second, we are particularly interested in the opportunities that SM offers to improve innovation performance by expanding the breadth, i.e. the openness, of a firm's search activities. The NPD process has been described as an activity of problem-solving and associated search processes (Koput, 1997; von Krogh and Koehne, 1998), with the objective to identify new ideas that have commercial potential. Firms often invest considerable resources in the search for such new innovative opportunities, as these investments increase their ability to create, use, and recombine new and existing knowledge (Larsen and Salter, 2006). In the context of OI, the objective of search is to identify external knowledge or external actors who can provide this knowledge (Jeppesen and Lakhani, 2010; Laursen, 2012). Earlier research has identified parameters to configure a successful search strategy, including its scope, timing, or contingencies of the innovation problem (Katila and Chen, 2008; Afuah and Tucci, 2012). By defining openness as a balance between search breadth and depth, Laursen and Salter (2006) shifted the focus on the search channels that firms use to identify innovative opportunities, such as suppliers, users, and universities. Other OI research 
has focused on the problem that needs to be solved (Felin and Zenger, 2014; Lakhani and Tushman, 2012), the way how the search process is initiated (Afuah and Tucci, 2012; Jeppesen and Lakhani, 2010), or decisions firms make about the boundaries and characteristics of the search field (Gulati et al., 2012).

This research complements and extends this research. Building on the perspective of search channels, this article introduces SM sources as a new channel with its own characteristics and particularities, providing access to the vast pool of user-generated content, and new sources of knowledge. By differentiating the information sought by the innovating firm (information about market needs or information about technical knowledge), we build on the problembased perspective of search. Finally, by investigating the influence of formalization of a firm's innovation process, this study investigates organizational factors influencing the search process. It hence contributes to the emerging perspective of OI as open search by investigating search strategies, their contingencies, and their performance effects in the context of SM.

Third, this article explores the role of complementarities between market (need) and technology (solution) related knowledge stocks for NPD. Previous research has focused either on the frontend of innovation or the development stage. This study reveals that firms searching in SM for both need information and for solution information have strong (positive) performance effects compared to firms that utilize SM as an information source for one of these information stocks only. Furthermore, it complements extant analyses of NPD success factors by empirically testing the relationship between the use of SM for NPD and firm performance across a number of industries. This study also investigates how complementarity effects between search activities and the adoption of a formalized NPD process impacts firm performance. 


\section{Social Media in Product Development}

$\mathrm{SM}$ is an all-encompassing term applied to various technologies that differ in scope and functionality (Kaplan and Haenlein, 2010; Kane et al., 2014). First, there are text-based applications like blogs and microblogs, e.g. Blogger and Twitter, or collaborative projects like Wikipedia and user forums. Other applications are dedicated to richer forms of media like video (e.g. YouTube), photographs (e.g. Flickr or Pinterest), music tracks (e.g. cc: Mixter), and in particular social networking sites such as Facebook and LinkedIn. Of great interest to innovating firms are the individuals, communities, and social networks that form around these platforms and create their content. SM employ web-based and mobile technologies which enable creativity as individuals and communities are able to share, co-create, discuss, and modify firm- and user-generated content (Kietzmann et al., 2011).

SM has become an important source of data and business intelligence, providing information about trends in the marketplace, intelligence about competitors' products, and feedback on those of the firm (Brem and Bilgram, 2015; Culnan, et al.; 2010; Kaplan and Haenlein, 2010). Using SM for market research extends information from traditional research methods. It also provides information in real time, which can hasten decision making processes and speed to market. Importantly, users of SM are able to play a more active role in the research and NPD process. For instance, Starbucks Ideas and Dell Ideastrom are well-popularized platforms where customers can share feedback, but also generate new offerings in form of an active dialogue amongst each other or with the company's management (Bayus, 2013). By analyzing existing user content in SM applications (Twitter, Facebook comments, and user forums), Nivea, the global cosmetic brand owned by Beiersdorf, obtained radical new customer insights, which resulted in the most successful launch of a new product for this company (Bilgram et al., 2011). Threadless, a Chicago based fashion company, has made the link between SM and NPD the core of its business model and is organized around a continuous 
stream of social interactions with its users. Recently, Brem and Bilgram (2015) highlighted the opportunities of using SM to search for market and technical information in business-tobusiness markets, citing examples from manufacturers of industrial hardware, automobile components, and transportation equipment.

As these examples illustrate, SM presents new opportunities to gather market information about customer needs, either by scanning existing user-generated content or by providing an infrastructure for idea generation and co-design by users.SM also offers opportunities to access technical knowledge, i.e. solution information. Füller et al. (2008) analyzed online communities focusing on basketball shoes and found that in these communities a small number of technology-savvy users did not just comment about existing products or express open needs, but also engaged in their own problem solving activities, developing new shoes, and later shared their innovative designs in the community. Marchi et al. (2011) studied the Ducati Motor Community and documented broad sharing of novel technical solution knowledge among its members. Similarly, Belz and Baumbach (2010) found that users shared extensive technical information in a social network built around sustainable food. Thus, SM promises new opportunities for OI (Kaplan and Haenlein, 2010). It provides firms access to novel insights and knowledge on a broad scale, reaching sources and domains previously untapped and thus increasing the openness of search for relevant knowledge. In the following we investigate whether increasing the openness of search by utilizing the new set of information sources offered by SM enhances innovation performance.

\section{Hypotheses Development}

\section{Social media and NPD performance}

The research model builds on the understanding of OI as a knowledge transfer process that purposively manages knowledge flows across organizational boundaries (West and Bogers, 
2014). This process builds on the collaboration of numerous actors, often organized by novel forms of information technology (Afuah and Tucci, 2012; Lakhani et al., 2012). Using SM as a source for such a knowledge flow into the firm is compatible with the notion by Laursen and Salter (2006), who regard openness as a function of search breadth and depth. Increasing the scope of search should lead to a more successful knowledge transfer, i.e. the acquisition of information required for an innovative task (Szulanski, 1996). Organizing an open search hence requires the selection of suitable external search channels, followed by a deep exploration of these sources (Katila and Ahuja, 2002).

A search strategy is considered to be an important mechanism that enables firms to learn and to develop their knowledge base (Köhler et al., 2012). Identifying and acquiring knowledge such as that found in the user communities that form around SM platforms require firms to have effective search strategies. The ability to follow an effective search strategy and to exploit external knowledge has been found to be pivotal for innovation performance (Nelson and Winter, 1982; Szulanski, 1996). Traditionally, firms engaged in rather localized search processes, following established trajectories, searching within known fields and with regard to knowledge that is familiar to the firm (Stuart and Podolny, 1996). Firms which are able to overcome these local tendencies and engage in more distant (open) search for relevant information, as opposed to local search, have shown higher innovative performance (Laursen, 2012; Jeppesen and Lakhani, 2010).This broader, more distant search enriches the firms' knowledge stocks by forging new connections with actors that can add new and distinctive insights. Firms can benefit substantially from utilizing this diverse set of external partners (Faems et al., 2010; Laursen and Salter, 2006). The vocal and creative users of SM arguably represent such a diverse source of external actors.

However, previous OI research has proposed that this is not a linear relation. The line of arguments by Laursen and Salter (2006) and results from earlier empirical studies (Katila and 
Ahuja, 2002; Leiponen and Helfat, 2010) suggests that openness of search has an inverse Ushaped relationship with performance. Over-searching, e.g. using SM sources, may negatively affect performance as there maybe too many inputs for the firm to manage and choose between (Koput, 1997). Also, ideas may come at the wrong time and in the wrong place to be fully exploited. Furthermore, when there is too much input, some ideas may be not taken seriously or given the required level of attention. Attention-based theory suggests that to achieve a competitive advantage, managers need to "focus their energy, effort, and mindfulness on a limited number of issues" (Ocasio, 1997, p. 203). Otherwise they are a not able to benefit from increasing the extent of external information utilized for an innovation project (Laursen and Salter 2006).

Summarizing, we expect that conducting a broader search by means of gathering information from multiple SM sources will have positive influence on innovation performance. But at the same time, companies may also tend to "over-search" which will have a negative effect on their ability to implement the external knowledge (Katila and Ahuja, 2002). This will, in the end, influence innovation performance negatively. Together, these arguments suggest that firms have to find the right extent of using social media as new channel of external search. Hence, we hypothesize:

H1.The relationship between using SM sources to gather information and NPD performance is curvilinear (takes an inverted U-shape).

\section{Social media and need information}

Understanding customers' expressed and latent needs is fundamental for the development of successful new products (Griffin and Hauser, 1993; Urban and Hauser, 2004).Such need information resides within the users and relates to market and customer preferences, desires, satisfaction, and purchasing motives. Better access to need-related information reduces the risk of failure due to a lack of "fit to market". In order to acquire information about customer 
needs, firms have traditionally engaged in market research activities such as personal interviews, surveys, or focus groups. Whilst these methods are useful, they are costly and not without limitations (Kozinets et al., 2008). Need information is often complex and "sticky", i.e. difficult to extract and understand (von Hippel, 2001). It is also often widely distributed (Köhler et al., 2012; Lakhani et al., 2012).

The huge numbers of SM users provide a new source of information created by a set of diverse external actors. Users of SM sites have been shown to express their needs and experiences more openly and more impartially in the relative anonymity of the internet than within a traditional market research setting (Kozinets et al., 2008). Insights from SM analysis may also offer access to unanticipated sources outside of the firms' current market. Users who are active on SM, not just reading but also contributing content, may not be representative of the firm's current target market, but may exhibit lead user characteristics. Lead users are driven by the motivation to solve an open problem of their own and hence engage in the active development of new concepts. They often freely reveal their solutions to other community-members and so to any observer of such a community (Füller et al., 2008).Their inputs often exhibit a higher level of originality than responses obtained by surveys of 'representative' customers using conventional market research, as they hold knowledge that is fundamentally distinct from both the knowledge of the general market and from market information generated within firms (Chatterji and Fabrizio, 2014).Thus, we hypothesize that:

\section{H2: Using a wide range of social media to acquire need information is positively} related to NPD performance.

\section{Social media and solution information}

Beyond information about customer needs and preferences, firms need to acquire or produce technical knowledge for an NPD outcome. Technical knowledge embodies the 'solution', which is information about how to apply a technology to transform customer needs into new 
products or services. Following the arguments of the attention-based theory, better solution information at the right time enables developers to engage in more directed problem-solving activities, enabling their project to meet cost and time-to-market objectives (Piller et al., 2012). In general, in the front end of NPD the focus is on access to need information, while in the development stage it is more about obtaining the right solution information.

The procedure to scan SM sources like expert forums via Netnography (Kozinets, 2002) is a good example of a corresponding practice. Contributors to forums or discussion boards with lead user characteristics often share not just their needs and problems, but also reveal technical concepts and solutions (Mahr and Lievens, 2012; Janzik and Raasch, 2011). Also, there are entire online communities dedicated to the discussion of technical knowledge. The same can be found on specialized Facebook pages. Similar to scanning SM sources for need information, opening innovation search to SM sources bearing technical information contributed by users and technical experts should positively enhance the innovation performance of a firm. Consequently, NPD teams may develop better technical solutions by transferring knowledge from another domain into their own. Thus we hypothesize that:

H3: Using a wide range of social media to acquire (technical) solution information is positively related to NPD performance.

\section{Complementarity effects}

The notion of complementarities has been investigated from different perspectives. As defined by Milgrom and Roberts (1995, p. 181) complementarity between activities is obtained if "doing more of one thing increases the returns of doing (more of) the others". In the context of managing innovation at the firm-level, the notion of complementarity has been used to understand the outcomes of technology diversification patterns (Granstrand et al., 1997). More specifically, it suggests that firms will profit most from new technologies when complementary new activities and practices are also adopted (Milgrom and Roberts, 1990). 
Laursen and Foss (2003), for example, show that new HR practices are most conducive to innovation performance when adopted as part of a system of mutually reinforcing practices.

Complementarity has also been conceptualized as an important source of path-dependence: successful change can only be achieved if many, perhaps all, relevant variables of a system are involved in specific ways (Ringberg and Reihlen, 2008; Lin and McDonough, 2011). Past experiences with one activity create expectations about action-outcome relationships of another. A lack of complementarities can explain the inability of an organization to profit from new (technological) opportunities (Milgrom et al., 1990). In the context of this study, the ability of a firm to benefit from external search in SM could depend upon complementary internal processes when organizing and conducting this activity. Organizations that adopt SM for NPD have to challenge their existing mental models of how information is gathered in order to evolve and improve their process. Conversely, when employees use inputs from new sources and think in new ways, external knowledge is more likely to be used in a profitable way (Senge, 1992). Building these activities and forming the beliefs and expectations is a long and enduring process. At the same time, the need to leverage complementarities requires firms to conduct more holistic searches in SM. Firms need to learn how to identify the most appropriate SM sites in the first place, and then how to use them proficiently (Roberts and Candi, 2014). As argued before, collecting information about customer needs may move NPD projects forward and achieve better fit-to-market and profitability. But need information can also provide guidance and act as a filter when searching for solution information at later stages of NPD. This may prevent over-search and help to define an optimal breadth of search from external sources (Leiponen and Helfat, 2010).

The relationship between need and solution information may also work in the opposite direction. Solution information gathered from SM may guide the project team to search for complementary information on corresponding market needs and filter the vast and fuzzy 
information about customer needs available through SM. Successful NPD projects depend on gathering both types of information in a complementary way (Choi, Poon and Davis, 2008). Following this line of argument we hypothesize:

H4: There is a complementary effect of using social media to acquire need information and using social media to acquire solution (technical) information on NPD performance.

\section{Formalization as a facilitator of open search}

Complementarities are subject of contingencies, too (Milgrom and Roberts, 1990). Utilizing SM sources simultaneously to search and acquire need and technical solution information requires internal structures to process this information (Gulati et al., 2012).Earlier research on OI has shown that firms need to build dedicated processes and internal capabilities to leverage its opportunities (Dahlander and Gann, 2010; Foss et al., 2011).Thus, the link between SM and performance may be influenced by structural and organizational decisions within the innovating firm. Previous research has especially emphasized the role of formalization of the NPD process (Barczak et al., 2008; Schultz et al., 2013), i.e. the degree to which roles, operating procedures, and ways of communication are defined and are used to govern the interaction between people (Child, 1972). Research on the influence of having a formal NPD process on performance provides a varied picture. Some view formalization as a bureaucratic constraint that impedes organizational flexibility, creativity, and the ability to learn (Killen and Hunt, 2013). Others have demonstrated empirically that formalization leads to success (Cooper, 2008; Cooper et al., 2002; Schultz et al., 2013). Research has also shown that one way to embed novel IT tools and to enhance their usage is to have a formal NPD process (Barczak et al., 2008).

This article adopts the latter perspective, suggesting that formalization of the NPD process facilitates better decision making, especially with regard to processing the information 
acquired from SM sources. Formalization helps to codify best practices and may be seen as a process-related capability-building mechanism that supports the diffusion and transformation of knowledge, making external knowledge easier to apply (Eisenhardt and Martin, 2000). It also provides an organizational memory that facilitates the diffusion of OI capabilities, for instance when and how to tap into external SM knowledge sources. Formalization helps to establish "guidelines" for communication and exchange, thereby improving a firm's capacity to apply the knowledge and improving cooperation among employees. This, in turn, builds sense of structure and reduces ambiguity (Pertusa-Ortega et al., 2010), enhancing the firm's ability to carry out the search process and utilize the resulting ideas and knowledge. Without formalization, external search and integration would suffer from being "disorganized, sporadic or ineffective" (Okhuysen and Eisenhardt, 2002: 383). We therefore hypothesize:

H5: A highly formalized NPD process together with the simultaneous use of social media to acquire need and solution information will lead to higher NPD performance.

\section{Methodology}

To test the hypotheses, this study draws on data from the 2012 PDMA CPAS (Markham and Lee, 2013).As the aim was to analyze the effect of SM usage, the data set was reduced to those companies that used at least one SM source (Heckman's (1979) two-step procedure confirmed that this sample reduction did not lead to a selection bias, as the selection parameter turned insignificant). This resulted in a sample of 186 companies for further analysis. All measures were drawn from the CPAS survey. Appendix A provides the items used in this study along with their means and standard errors. All explanative items are formative measures. Because formative indicators are not necessarily inter-correlated, reliability in terms of internal consistency and convergent validity are irrelevant in this case (Diamantopoulos and Winklhofer, 2001). 
Dependent variable: NPD performance. There is no commonly established measure of innovation success (Griffin and Page, 1996; Manion and Cherion, 2009). It is important therefore to match the success measure as closely as possible to the research objectives (Craig and Hart, 1992).Following the nature of the CPAS survey (Barczak, Griffin and Kahn, 2009), a project-focused measure was used for the dependent variable: the degree of achievement in terms of meeting typical objectives of NPD projects, differentiating between projects targeting incremental, more innovative, and radical innovation (Song and Thieme, 2009). The CPAS survey considers this degree of innovativeness as a kind of contingency factor: the idea is that a project manager has an ex-ante opinion about the degree of innovativeness the project should achieve. Hence, they plan and execute the project accordingly. Song and Thieme (2009), for example, show that supplier integration has both positive and negative effects on innovation performance depending whether the project is radical or incremental. Their results confirm the basic assumption that success factors to manage a radical or an incremental innovation project may differ fundamentally.

For each project type, four innovation performance variables were taken from the CPAS survey. Respondents were asked to indicate the percentage of projects introduced into the market during the last five years that were meeting technical objectives, market objectives, time objectives, and cost targets. Those percentages were collected separately for the three different types of innovation and the arithmetic mean was calculated (Holahan, Sullivan, and Markham, 2014). Overall, measurement follows the logic that new product development success is based on both effectiveness (fit with customer demands, meeting technical objectives) and efficiency (being cost effective and at the right time at the market.

Independent variable: This article has introduced SM as a new channel for integrating external knowledge into the innovation process, complementing conventional channels. To measure the main construct, breadth of search using SM, two CPAS items were used which 
asked respondents to indicate to what extent they used eleven different SM tools, either to gather need information about customers and products, or to gather solution information to solve technical problems, using a 5-point Likert-type scale ( $1=$ never, 5 = virtually always $)$. The SM tools were specified by the CPAS survey (Appendix A). Because the intensity of using a SM tool is not necessarily connected with the usage intensity of another, this measure has a formative nature (Diamantopoulos and Winklhofer, 2001). Therefore, three different $S M$ indices have been developed: Following Laursen and Salter (2006), each of the eleven tools was coded as a binary variable, with 0 representing "no use" and 1 "use". This was done for both classes of information acquired from SM sources. All binary variables were added up. A higher number (in the range of 1-22) of the measure SM Overall hence reflects a "broader" use of SM. To test H1, this variable was standardized and squared. To test $\mathrm{H} 2$ and H3, i.e. to understand the performance implications of utilizing SM for different kind of information demands, two further SM variables were developed: SM Need Information and SM Solution Information, constructed as an index of SM usage (the standardized average value score of all items). These variables can be interpreted as the extent of using SM to get access to need information or solution information, respectively.

Process Formalization: In order to measure the formalization of the NPD process, a CPAS question was utilized that asked respondents which of four items would describe their NPD process best. Analysis of H4 follows Zollo et al. (2002) and builds on a dummy variable to indicate whether the companies have a highly or a less formalized process. Splitting the sample at the median, all companies indicating that they have a highly formalized process were coded with 1 ( 0 for the remaining firms).

Control variables: Research by de Brentani and Kleinschmidt (2004) identified a positive effect of innovation culture for NPD. Respondents were presented with different cultural values. Using a 5-point Likert-type scale, an index of innovation culture as the average value 
score of all items was constructed (standardized). We also controlled for the impact of innovation barriers. Respondents were presented with eight different barriers to adoption of novel NPD tools. A higher number of barriers was assumed to lead to higher resistance towards the adoption of SM as a new tool. The eight barriers were added so that a firm gets a 0 when no barriers exist and an 8 when all barriers are present.

Firm size was measured by standardized sales. We controlled for absorptive capacity using the inverted $R \& D$ intensity (Ritala and Humerelinna-Laukkanen, 2013) and standardized it. To control whether globalized firms are more open to use SM than non-globalized firms, a dummy variable was constructed, coding companies operating in more than two countries with 1 , and the remaining companies with 0 . To control for differences between $B 2 B$ versus $B 2 C$ oriented companies, firms which sell more than $50 \%$ to $\mathrm{B} 2 \mathrm{C}$ with were coded with 0 , companies which sell $50 \%$ to both with 1 , and companies which sell more than $50 \%$ to B2B with 2. Companies considering themselves as "high-tech" were coded with 0, companies with $50 \%$ "high-tech and "low-tech" with 1, and those with more than 50\% "low-tech" with 2. Similarly, companies which spent more than $50 \%$ of their total NPD budget on goods (product oriented companies) were coded with 1, and service oriented firms with 0.

\section{Results}

Overall, the CPAS data revealed that companies who utilize SM apply these tools on average in $42 \%$ of their projects (Table B1 provides more descriptive data). Companies operating in B2B markets in a high-tech environment are using SM tools more intensively than B2C companies in less technology-driven domains. Likewise, companies operating more globally also use SM more intensively. When splitting the use of SM channels into searching for need or for solution information, this study finds that SM is used rather to gather need information than to access solution information. Need information is collected predominately from 
discussion forums (31\%), followed by branded social networks (26\%), blogs (25\%), and social networks (23\%). Solution information tends to be gathered by rather text-based SM tools, e.g. discussion forums (29\%), blogs (23\%), and Wikis (20\%).

To test the hypotheses, first control variables were entered, then the main effect terms, and finally the interaction terms (Baron and Kenny, 1986). Collinearity was checked among the formative indicators by assessing variance inflation factors and did not cause any problem: the maximum variance inflation factor was 2.44 for SM Solution Information and the minimum 1.04 for $R \& D$ Intensity. All values are far below the cutoff threshold of 3.3 recommended for formative constructs (Kuester et al., 2012). Coefficients were standardized for better interpretation and to limit the potential of multi-collinearity (Aiken and West, 1991). Hypotheses were tested with OLS regressions.

To examine robustness, a number of additional post-hoc analyses were performed. All models were re-estimated using Tobit regressions instead of OLS. We found a consistent pattern in all models. To analyze the robustness of our results to the omission of specific control variables, we sequentially eliminated single control variables (Gesing et al., 2015), which led to consistent results. A set of industry dummies was included to capture systematic differences in innovation success across the different groups.

Table 1 presents the results for $\mathrm{H} 1-\mathrm{H} 4$ with robust standard errors. The Baseline model contains only controls. Model 1 adds SM Overall and its squared term. While the expected inverted U-shaped effect could be confirmed, i.e. that the relationship between using SM sources to gather information and NPD performance is curvilinear, the findings surprisingly indicate that a more intensive (broad) use of SM has a significant negative effect on NPD performance, and not a positive one. Thus, H1can be confirmed. However, while there is a strong significant effect for incremental and more innovative projects, the effect for radical projects is only on a $10 \%$ level. 
Model 2a differentiates between using SM to gather need information and to access solution information. As expected, utilizing need information from SM channels has a significant positive performance effect, but again only for more innovative and for incremental projects. Therefore, H2 cannot be fully confirmed. Searching for technical solution information in SM, however, surprisingly shows a (strong) negative performance effect for all three types of projects. The strength of this effect also explains the negative effect found in Model 1. Thus, H3 is not supported.

Model 2b analyzes the complementarity effect of searching for need and solution information in SM simultaneously. In order to test for complementarity in the performance equation, an interaction term between SM Need and SM Solution Information was specified in an OLS regression model. This allowed us to test whether the marginal effect of one of these activities raises when the other is increased. The results indicate a strong positive and significant interaction effect, consistent with the prediction of complementarity (Laursen and Salter 2006; Poppo and Zenger, 2002). Using SM for both need and for solution information simultaneously has a significant positive effect on NPD performance for all three project types. Thus H4 is supported.

Add here: << Table 1: Analysis of $\mathrm{H} 1, \mathrm{H} 2$, and $\mathrm{H} 3$ : The link between project performance and utilization of information from social media sources $>>$

Model 3 investigates how the link between using SM and innovation performance is moderated by high or low formalization (Table 2). Overall, high formalization and the simultaneous use of SM to acquire need and solution information has a significant positive effect on performance for incremental and more innovative projects. To augment the results 
of the regression analyses regarding the moderating effects of formalization (Appendix B), we further analyzed the relationships using post-hoc probing of the simple slopes (Aiken and West, 1991; Dawson, 2014), also plotting the impact of formalization on the marginal effect of performance (Brambor, Clark, and Golder, 2006). For more innovative NPD projects, the simple slope analysis shows only significant values for the slopes (1) to (4) and (2) to (4) (p< 0.05). Therefore, only these two cases can be interpreted (Dawson, 2014). Overall formalization matters: having a highly formalized process and searching for need and solution information in SM simultaneously leads to higher NPD performance. Likewise, the same effect exists for incremental NPD projects (only significant values for slopes (1) to (4) and (2) to (4); $p<0.05)$, again demonstrating that formalization has a strong effect. Model 3 can be interpreted as a three-way interaction effect: With the simultaneous use of SM for gathering both need and solution information, innovation performance increases, but only for firms with a high level of process formalization. Due to the non-significant results concerning radical projects, H5 is supported only partially.

Add here: $<<$ Table 2: Analysis of $\mathrm{H} 4$ and H5: Moderating role of process formalization $>>$

\section{Discussion}

By analyzing SM as a new source to access external knowledge for NPD, such as usergenerated content, this article extends the concept of openness in innovative search and responds to calls for research that connects OI and information technology (Nambisan, 2013). Interest in the OI paradigm has often been driven by the belief that firms profit from access to external sources of knowledge in general. However, the results suggest that scholars and practitioners need to take a more fine grained perspective when utilizing information from new and unstructured sources such as SM. 


\section{Implications for theory}

Building on Szulanski (1996), OI can be considered as a knowledge transfer process with search as its central activity, i.e. the identification and acquisition of relevant information required for an innovative task. Laursen and Salter (2006) proposed that a broader scope of search should lead to a more successful knowledge transfer. Earlier research has identified the parameters to configure a successful search strategy, including its timing and the selection of suitable external search channels (Afuah and Tucci, 2012; Rosenkopf and Nerkar, 2001). Therefore, scanning SM sources demands purposive decisions about the boundaries and characteristics of the search field, and expectations about the requirements of a knowledge source, like represented expertise or market coverage (Gulati et al., 2012).

The empirical models support this theoretical perspective. Utilizing information from SM sources for NPD can increase innovation performance on the project level, but only for certain types of innovation and under specific conditions. The CPAS survey allowed to distinguish between different types of SM and to control for various conditions characterizing the innovating firm. This analysis shows that searching in SM sources to gather information about market and customer needs can improve NPD performance. This effect, however, is not as strongly as expected and is only significant for more innovative projects. Still, the results extend the common call to incorporate the "voice of the customer (VOC)" at the frontend of innovation (Griffin and Hauser, 1993; Urban and Hauser, 2004) by providing empirical evidence on new, contemporary sources of external market knowledge, which move the firm outside of their established VOC routines. Essentially, SM provides a different vista into the lives of customers giving access to information that was previously difficult to collect. SM platforms such as Facebook and Twitter have made possible an explosion of self-reporting, providing product developers with a huge reservoir of data that can be utilized for NPD. Firms are able to observe and follow the conversations of their customers and track their likes 
and dislikes, building an in-depth understanding and appreciation of customers' requirements, problems, operations, and systems. In addition, SM provides a new conduit for customer expression enabling users to play a more active co-creative role in the research and NPD process. This resonates and connects with the emerging literature on customer co-creation for NPD (Gemser and Perks, 2015), and supports calls for a more user-centric perspective on OI (Randhawa et al., 2016).

Previous literature has focused less upon the utilization of SM to acquire technical solution information. Solution information is essentially concerned with how to apply a technology to transform customer needs into new products. The strong negative performance effect found in the analysis is surprising, indicating that using no information at all from SM to solve technical problems would position a firm better than searching in SM sources for such information. Whilst the participatory nature and heterogeneity of users of SM is considered advantageous, it may also have unintended consequences. The effort of identifying relevant information and seeing connections amongst in such large data sets appears challenging. While most businesses today have developed extensive expertise in using traditional market research activities, they still are learning how to use SM sites proficiently (Roberts and Candi, 2014). Furthermore, Daft and Lengel (1986) have argued that more and new information will not automatically reduce uncertainty to solve a given problem (innovative task), but can also be confusing and even increase perceived uncertainty. The same pattern may explain the performance outcomes of using SM for technical problem solving.

To better understand the divergent utility of SM sources for need versus technical solution information, the analysis was extended to study complementarities between the two types of information. The results indicate that in companies who extensively search for both need and solution information, the negative performance effect diminishes and the overall effect turns positive. This confirms earlier research suggesting that purposively expanding the breadth of 
search in external sources enhances innovation performance (Leiponen and Helfat, 2010). In particular, collecting information about customer needs may provide important input, which helps to move a project forward. Also, a firm's mentality of "tech push" may be counterbalanced by the market insights gathered in the earlier stages of development (Urban and Hauser, 2004). Past experience with collecting one kind of information may allow a more informed choice about collecting the other, leading to better utilization of resources (Ringberg and Reihlen, 2008). Hence, searching for need information in the early stages of NPD may lead to learning about the different types and functionalities of SM. In turn, this may facilitate a more precise and responsible analysis of information derived from SM sources in the development stage. Thus, need information may act like a filter to improve the efficiency of search for technical information. This study is, to the best of our knowledge, the first to explicitly investigate the complementarities between market-related and technology-related information in an OI context.

Consistent with earlier work (Afuah and Tucci, 2012; Gulati et al., 2012), the link between openness of search and innovation performance seems also to be dependent upon the firm's organizational design. We specifically looked into formalization of the NPD process. Prior research provides contradictory arguments with regard to the advantages and disadvantages of high versus low formalization. The results of this study confirm the understanding that formalization improves NPD performance (Cooper et al., 2002; Schultz et al., 2013). A formalized NPD process provides controls and helps to reduce uncertainty and mitigates risk. These controls, plus institutionalized pathways and project procedures, give a structure and sequence for the flow of activities, providing clarity around what is required by whom and how the acquired information is to be utilized and processed (Barczak et al., 2008; Schultz et al., 2013). Firms that have no formal processes in place lack this type of guidance. As anticipated, firms with no formalization are not able to profit from the use of SM at all. In this 
regard, this study complements the earlier discussions of formalization in the OI literature (Dahlander and Gann, 2010; Foss et al., 2011).

The findings further support earlier research that identified the degree of innovativeness as a core contingency in managing NPD (Cooper, 2008; Holahan, Sullivan, and Markham, 2014). The CPAS survey recognizes the degree of innovativeness as an ex-ante perception of a project manager once an innovation process has started. Interestingly, empirical results are robust for incremental and more innovative innovation projects, but indicate only weak (significant) effects for radical projects. One would have assumed that the more managers perceive uncertainty due to a larger degree of innovativeness, the more they would strive to reduce this uncertainty by acquiring relevant external information and the more they would allocate dedicated resources to search in SM sources. But as the results indicate, more information seems not automatically to reduce uncertainty and lead to higher performance. It can be confusing, especially when there are multiple interpretations in a given situation. In well-structured, clear situations, i.e. situations of incremental innovation, managers are able to utilize more external information easily to reduce uncertainty and hence positively impact performance. For ambiguous, unstructured tasks, i.e. situations striving for more radical innovation, managers may first engage in a debate on search terms and possible sources for this information, before engaging in rich conversation exchanging ideas of how to interpret and apply the external information. The latter behavior may even explain the overall negative effect on NPD performance, as strongly indicated by the data for those companies using input from SM sources to solve technical problems by searching for solution information.

Utilizing SM for NPD is also contingent upon the firms' willingness to experiment with new external sources of information and forms of search. Here, organizational culture plays an important part in creating a supportive working environment that enables managers to experiment with SM and to open their search activities further (de Brentani and Kleinschmidt, 
2004). Innovation culture acts as an important control of the results of this study, enhancing the performance effects. From a process perspective, applying SM for the first time in the NPD process can be regarded as a novel, risky endeavor. As shown for the adoption of other novel IT tools for opening NPD (Barczak et al., 2008; Lüttgens et al., 2014), SM usage may be trigged by a few key individuals who display personal curiosity and engage in applying SM without a formal mandate of their superiors. However, the fact that these individuals are able to engage in this type of activity is a reflection of a culture for innovation within their organization. A willingness to experiment, a tolerance of mistakes, and the ability to learn are all aspects of such a culture (Terziovski, 2010). In unison, a strong innovation culture also prevents "not invented here", i.e. guarantees that the external information acquired via SM is also utilized for NPD.

\section{Managerial implications}

Extending the idea of OI by openly searching and utilizing information from the millions of users that are contributing to SM platforms is far from simple, and many firms are still on a learning curve. Overall, this study shows that utilizing information from SM can be beneficial for performance and may lead to competitive advantage, but it also suggests that this effect will not come automatically. Although firms may be competent in knowledge search in conventional information channels, the analysis suggests that managing SM inputs is different from managing other OI relationships. Just having a Facebook page or Twitter account will not suffice, and managers must understand the complexity of the process and challenges involved if they are to reap the rewards.

First, firms need a clear SM strategy for innovation. This includes understanding the different SM platforms and making strategic decisions about their use. The contingencies of the SMperformance link identified in this study highlight the need to carefully consider what type of information is required at the different stages of the NPD process. For instance, if the aim is to 
gather information about market needs and customer preferences at the front end of the NPD process, managers may want to consider using techniques such as Netnography within consumer forums or on social networking sites. Given the positive performance effect we found for these practices, we encourage managers to start their SM endeavors in NPD by such an activity. Managers who are looking for unconventional technical solution information to expand their solution space need a different strategy. They have to carefully define a search strategy, identifying key contributors (experts) on technical forums or wikis, and then engage in a personal conversation with these individuals to get access to purposeful knowledge for their innovation project. Although, need and solution information is often collected, analyzed and utilized by different departments, this study suggests that there is a need for an integrated and coordinated approach if firms are to leverage the complementarity effect.

This article also indicates that utilizing SM for innovation comes at a cost and requires resources, new skills, new procedures, competences to interpret and evaluate the information derived from SM, and a dedicated organizational design (Roberts and Piller, 2016). These skills and competences may be related to those currently built in pioneering firms for the analysis of "big data" (Davenport and Patil, 2012). These analytical skills are rather different to the capabilities conventionally connected with "open innovation readiness" (Foss et al., 2011). However, SM is not just about 'listening into' (Urban and Hauser, 2004) the domain of customers and users, but it also is about co-creating and interacting with them (Piller et al., 2012). Users engage with SM first and foremost for social relationships and social fulfillment (Majchrzak et al., 2013). As such, they cannot be managed in the same way as suppliers for external technology. Firms need to first recognize why users are willing to invest in time and resources to interact with them, what are the objectives of this conversation, and what are its borders and constrains. Companies that want to explore further the core idea of 'social' in SM need to ask whether they want a real dialogue with contributors to SM or whether they prefer 
to remain 'lurkers' and observers. Those firms wanting to engage into a richer, more interactive mode need to learn how to maintain a continuous conversation. Managers may, for instance, be intrigued to use SM tools such as Facebook groups for testing and getting feedback on early prototypes and concepts. However, by doing so, they may reveal too much to the public, confirming the earlier argument that too much openness is harmful for firm performance. Again, this research indicates that SM for NPD demands a balanced view, but also calls for more research in this domain.

\section{Limitations and further research}

The major limitation of this article is also one of its strengths. Data and measurement models relied on the PDMA CPAS survey, which provides a broad and extensive insight into the NPD practices and their performance implications of global firms. The survey instrument focused on SM as a source for need and solution information, but did not explicitly consider the opportunities of SM as a novel tool for knowledge sharing and interacting with customers and users. Also, one of the challenges of utilizing SM for NPD is the evolving nature and plethora of SM platforms that are available. Firms may increase the number and change the type of platforms they use overtime as they become more proficient in their usage. This an area that would benefit from longitudinal research as advocated by Perks and Roberts (2013).

Due to the large number of variables and controls in our model and the relative small numbers of respondents per industry, no distinction could be made between different industries in our regression analysis (our post-hoc analysis also revealed no differences). Nonetheless, the comparison between heavy users of SM and the rest indicated that there are distinct usage types (Markham and Lee, 2013). Future research should investigate these differences in more detail. Finally, future research could test the complementarity effect between SM for need and for solution information in greater detail, enabling companies to define better search practices for OI. For example, there may be complementarities between different types of SM. Also, 
following Milgrom and Roberts' (1995) original argument on complementarities of new technologies and organizational structure, future research should also look more intensively into structures and organizational designs that complement SM for NPD.

\section{References}

Afuah, A. and C. L. Tucci. 2012. Crowdsourcing as a solution to distant search. Academy of Management Review 37(3): 355-375.

Aiken, L. S. and S. G. West. 1991. Multiple Regression: Testing and Interpreting Interactions. Newbury Park: Sage.

Antons, D., R. Kleer and T. O. Salge. 2015. Mapping the Topic Landscape of JPIM, 19842013: In Search of Hidden Structures and Development Trajectories. Journal of Product Innovation Management, forthcoming doi: 10.1111/jpim.12300.

Barczak, G., A. Griffin and K. Kahn. 2009. Trends and drivers of success in NPD practices: Results of the 2003 PDMA best practices study. Journal of Product Innovation Management 26 (1): 3-23.

Barczak, G., E. J. Hultink and F. Suktan. 2008. Antecedents and consequences of information technology usage in NPD. Journal of Product Innovation Management 25(6): 620-631.

Baron, R. M. and D. A. Kenny. 1986. The moderator-mediator variable distinction in social psychological research. Journal of Personality and Social Psychology 51(6): 1173.

Bayus, B. L. 2013. Crowdsourcing new product ideas over time: An analysis of the Dell IdeaStorm community. Management Science 59(2): 226-244.

Belz, F. M. and W. Baumbach. 2010. Netnography as a method of lead user identification. Creativity and Innovation Management 19(3): 304-313.

Bilgram, V., M. Bartl and S. Biel. 2011. Getting closer to the consumer: How Nivea cocreates new products. Marketing Review St. Gallen 28(1): 34-40.

Brambor, T., W. R. Clark and M. Golder. 2006. Understanding interaction models: Improving empirical analyses. Political Analysis 14(1): 63-82.

Brem, A. and V. Bilgram. 2015. The search for innovative partners in co-creation: Identifying lead users in social media through netnography and crowdsourcing. Journal of Engineering and Technology Management37: 40-51.

Chatterji, A. K. and K. R. Fabrizio. 2014. Using users: When does external knowledge enhance corporate innovation? Strategic Management Journal 35(10): 1427-1445.

Chesbrough, H. 2003. Open Innovation: The New Imperative for Creating and Profiting from Technology. Boston: HBS Press.

Child, J. 1972. Organizational structure, environment and performance. Sociology 6(1): 1-22. 
Choi, B., S. K. Poon and J. G. Davis. 2008. Effects of knowledge management strategy on organizational performance: A complementarity theory-based approach. Omega 36(2): 235-251.

Cooper, R. 2008. The Stage-Gate idea-to-launch process - update, what's new, and Nexgen systems. Journal of Product Innovation Management 25(3): 213-232.

Cooper, R., S. Edgett and E. J. Kleinschmidt. 2002. Optimizing the stage-gate process: what best-practice companies do. Research-Technology Management 45(6): 43-49.

Craig, A. and S. Hart. 1992. Where to now in new product development research? European Journal of Marketing 26(11): 1-49.

Culnan, M. J., P. J. McHugh and J. Zubillaga. 2010. How large US companies can use Twitter and other social media to gain business value. MIS Quarterly Executive 9(4): 243-259.

Daft, R. L., and R. H. Lengel. 1986. Organizational information requirements, media richness and structural design. Management Science 32(5): 554-571.

Dahlander, L. and D. Gann. 2010. How open is innovation? Research Policy 39(6): 699-709.

Davenport, T. and D. Patil. 2012. Data scientist: the sexiest job of the 21st century. Harvard Business Review 90(10): 70-78.

Dawson, J. F. 2014. Moderation in management research: What, why, when, and how. Journal of Business and Psychology 29(1): 1-19.

De Brentani, U. and E. J. Kleinschmidt. 2004. Corporate culture and commitment: Impact on performance of international new product development programs. Journal of Product Innovation Management 21(5): 309-333.

Diamantopoulos, A. and H. Winklhofer. 2001. Index construction with formative indicators: An alternative to scale development. Journal of Marketing Research 38(2): 269-77.

Eisenhardt, K. M. and J. Martin. 2000. Dynamic capabilities: What are they? Strategic Management Journal 21(10): 1105-1121.

Faems, D., M. De Visser, P. Andries and B. Van Looy. 2010. Technology alliance portfolios and financial performance: value-enhancing and cost increasing effects of open innovation. Journal of Product Innovation Management 27(6): 785-796.

Foss, N. J., K. Laursen and T. Pedersen. 2011. Linking customer interaction and innovation: Mediating role of new organizational practices. Organization Science 22(4): 980-999.

Füller, J., K. Matzler and M. Hoppe. 2008. Brand community members as a source of innovation. Journal of Product Innovation Management 25(5): 608-619.

Gemser, G., and H. Perks. 2015. Co-creation with customers: an evolving innovation research field. Journal of Product Innovation Management 32(5): 660-665.

Gesing, J., D. Antons, E. P. Piening, M. Rese and T. O. Salge. 2015. Joining forces or going it alone? The interplay among external collaboration partner types, interfirm governance modes, and internal R\&D. Journal of Product Innovation Management 32(3): 424-440. 
Granstrand, O., P. Patel and K. Pavitt. 1997. Multi-technology corporations: "Distributed" rather than "distinctive core" competencies. California Management Review 39(4): 8-25.

Griffin, A. and A. L. Page. 1996. PDMA success measurement project: recommended measures for product development success and failure. Journal of Product Innovation Management 13(6): 478-496.

Griffin, A. and J. Hauser. 1993. The voice of the customer. Marketing Science 12(1): 1-27.

Gulati, R., P. Puranam and M. Tushman. 2012. Meta-organization design: Rethinking design in interorganizational and community contexts. Strategic Management Journal 33(6): 571-586.

Heckman, J. 1979. Sample selection bias as specification error. Econometrica 47(1): 153-161.

Holahan, P. J., Z. Sullivan and S. K. Markham. 2014. Product development as core competence: how formal product development practices differ for radical, more innovative, and incremental innovations. Journal of Product Innovation Management 31(2): 329-345.

Janzik, L. and C. Raasch. 2011. Online communities in mature markets. International Journal of Innovation Management 15(4): 797-836.

Jeppesen, L. B. and K. Lakhani. 2010. Marginality and problem-solving effectiveness in broadcast search. Organization Science 21(5): 1016-1033.

Kane, G., M. Alavi, G. Labianca and S. Borgatti. 2014. What's different about social media networks? MIS Quarterly 38(1): 275-304.

Kaplan, A. M. and M. Haenlein. 2010. Users of the world, unite! The challenges and opportunities of social media. Business Horizons 53(1): 59-68.

Katila, R. and G. Ahuja. 2002. Something old, something new: a study of search behavior and new product introduction. Academy of Management Journal 45(6): 1183-1194.

Kietzmann, J., K. Hermkens, I. McCarthy and B. Silvestre. 2011. Social media? Get serious! Understanding the functional building blocks of social media. Business Horizons 54(3): 241-251.

Killen, C. P. and R. Hunt. 2013. Robust project portfolio management: capability evolution and maturity. International Journal of Managing Projects in Business 6(1): 131-151.

Koput, K. 1997. A chaotic model of innovative search. Organization Science 8(5): 528-542

Köhler, C., W. Sofka and C. Grimpe. 2012. Selective search, sectoral patterns, and the impact on product innovation performance. Research Policy 41(8): 1344-1356.

Kozinets, R. V. 2002. The field behind the screen: using Netnography for marketing research in online communities. Journal of Marketing Research 39(1): 61-72.

Kozinets, R. V., A. Hemetsberger and H. J. Schau. 2008. The wisdom of consumer crowds collective innovation in the age of networked marketing. Journal of Macromarketing 28(4): 339-354. 
Kuester, S., C. Homburg and S. C. Hess. 2012. Externally directed and internally directed market launch management. Journal of Product Innovation Management 29(S1): 38-52.

Lakhani, K., M. Tushmann and H. Lifshitz-Assaf. 2012. Open innovation and organization design. Journal of Organization Design 1(1): 24-27.

Laursen, K. 2012. Keep searching and you'll find: variety creation through firms' search activities for innovation? Industrial and Corporate Change 21(5): 1181-1220.

Laursen, K. and A. Salter. 2006. Open for innovation: the role of openness in explaining innovation performance among UK manufacturing firms. Strategic Management Journal 27(2): 131-150.

Laursen, K. and N. J. Foss. 2003. New human resource management practices, complementarities, and the impact on innovation performance. Cambridge Journal of Economics 27(2): 243-263.

Leiponen, A and C. Helfat. 2010. Innovation objectives, knowledge sources, and the benefits of breadth. Strategic Management Journal 31(2): 224-236.

Lin, H. E. and E. F. McDonough III. 2011. Investigating the role of leadership and organizational culture in fostering innovation ambidexterity. IEEE Transactions on Engineering Management 58(3): 497-509.

Lüttgens, D., P. Pollok, D. Antons and F. Piller. 2014. Wisdom of the crowd and capabilities of a few: internal success factors of crowdsourcing for innovation. Journal of Business Economics 84(3): 339-374.

Mahr, D. and A. Lievens. 2012. Virtual lead user communities: Drivers of knowledge creation for innovation. Research Policy 41(1): 167-177.

Majchrzak, A., S. Faraj, G. C. Kane and B. Azad. 2013. The contradictory influence of social media affordances on online communal knowledge sharing. Journal of ComputerMediated Communication 19(1): 38-55.

Manion, M.T., and J. Cherion. 2009. Impact of strategic type on success measures for product development projects. Journal of Product Innovation Management 26(1): 71-85.

Marchi, G., C. Giachetti and P. de Gennaro. 2011. Extending lead-user theory to online brand communities: The case of the community Ducati. Technovation 31(8): 350-361.

Marion, T. J., G. Barczak and E. Hultink. 2014. Do social media tools impact the development phase? Journal of Product Innovation Management 31(S1): 18-29.

Markham, S. K. and H. Lee. 2013. Product Development and Management Association's 2012 comparative performance assessment study. Journal of Product Innovation Management 30(3): 408-429.

Milgrom, P. and J. Roberts. 1990. The economics of modern manufacturing. The American Economic Review 80(3): 511-528.

Milgrom, P. and J. Roberts. 1995. Complementarities and fit: Strategy, structure, and organizational change in manufacturing. Journal of Accounting and Economics 19(2): 179-208. 
Nambisan, S. 2013. Information technology and product/service innovation. Journal of the Association for Information Systems 14(4): 215-226.

Nelson, R. and S. G. Winter. 1982. An Evolutionary Theory of Economic Change. Cambridge, Massachusetts: Harvard University Press.

Ocasio, W. 1997.Towards an attention-based view of the firm. Strategic Management Journal 18 (Special Issue: Organizational and Competitive Interactions): 187-206.

Okhuysen, G. A. and K. Eisenhardt. 2002. Integrating knowledge in groups: how formal interventions enable flexibility. Organization Science 13(4): 370-386.

Perks, H. and D. L. Roberts. 2013. A review of longitudinal research in the product innovation field with discussion of utility and conduct of sequence analysis. Journal of Product Innovation Management 30(6): 1099-1111.

Pertusa-Ortega E. M., P. Zaragoza-Sáez and E. Claver-Cortés. 2010. Can formalization, complexity, and centralization influence knowledge performance? Journal of Business Research 63(3): 310-320.

Piller, F., A. Vossen and C. Ihl. 2012. From social media to social product development: the impact of social media on co-creation of innovation. Die Unternehmung 66(1): 7-27.

Poppo, L. and T. Zenger. 2002. Do formal contracts and relational governance function as substitutes or complements? Strategic Management Journal 23(8): 707-725.

Randhawa, K., R. Wilden and J. Hohberger. 2016. A bibliometric review of Open Innovation: setting a research agenda. Journal of Product Innovation Management forthcoming doi: 10.1111/jpim.12312.

Ringberg, T. and M. Reihlen. 2008. Towards a socio-cognitive approach to knowledge transfer. Journal of Management Studies 45(5): 912-935.

Ritala, P. and P. Hurmelinna-Laukkanen. 2013. Incremental and radical innovation in coopetition. Journal of Product Innovation Management 30(1): 154-169.

Roberts, D. and F. Piller. 2016. Finding the right role for social media in innovation. MIT Sloan Management Review 57(3): 41-49.

Roberts, D. L. and M. Candi. 2014. Leveraging social network sites in new product development. Journal of Product Innovation Management 31(S1): 105-117.

Rosenkopf, L., and A. Nerkar. 2001. Beyond local search: Boundary-spanning, exploration, and impact in the optical disk industry. Strategic Management Journal 22(4): 287-306.

Schultz, C., S. Salomo, U. de Bretani and E. Kleinschmidt. 2013. How formal control influences decision making clarity and innovation performance. Journal of Product Innovation Management 30(3): 430-447.

Senge, P.M. 1992. Mental models. Planning Review 20(2): 4-44.

Song, M. and J, Thieme. 2009. Role of suppliers in market intelligence gathering for radical and incremental innovation. Journal of Product Innovation Management 26(1): 43-57. 
Stuart, T. E. and J. Podolny. 1996. Local search and the evolution of technological capabilities. Strategic Management Journal 17(1): 21-38.

Szulanski, G. 1996. Exploring internal stickiness: Impediments to the transfer of best practices within the firm. Strategic Management Journal 17(S2): 27-43.

Terziovski, M. 2010. Innovation practice and its performance implications in SME in the manufacturing sector. Strategic Management Journal 31(8): 892-902.

Urban, G. L. and J. Hauser. 2004. Listening in to find and explore new combinations of customer needs. Journal of Marketing 68(2): 72-87.

von Hippel, E. 2001. Perspective: User Toolkits for Innovation. Journal of Product Innovation Management 18(4): 247-257.

West, J. and M. Bogers. 2014. Leveraging external sources of innovation. Journal of Product Innovation Management 31(4): 814-831.

Zollo, M., J. J. Reuer and H. Singh. 2002. Interorganizational routines and performance in strategic alliances. Organization Science 13(6): 701-713. 


\section{Appendix A: Core Measurement Items and Descriptive Data}

\begin{tabular}{|c|c|c|c|c|c|}
\hline Measures & $\begin{array}{l}\text { CPAS } \\
\text { Item \# }\end{array}$ & Description & Mean & $S E$ & ViF \\
\hline \multirow[t]{2}{*}{$\begin{array}{l}\text { NPD } \\
\text { Performance }\end{array}$} & $\begin{array}{l}B \\
W \\
W\end{array}$ & \multicolumn{4}{|c|}{$\begin{array}{l}\text { Based upon your Business Unit's definition of a successful new product, about } \\
\text { what\% of all the new products introduced into the market during the last } 5 \text { years } \\
\text { were successful? }\end{array}$} \\
\hline & Radical & $\begin{array}{l}\text { - } \quad \% \text { projects that met technical objectives } \\
\text { - } \quad \% \text { projects that met market objectives } \\
\text { - } \quad \% \text { projects on time } \\
\text { - } \quad \% \text { projects on budget }\end{array}$ & $\begin{array}{l}58.56 \\
51.77 \\
32.41 \\
35.96\end{array}$ & $\begin{array}{l}28.57 \\
28.43 \\
27.65 \\
29.42\end{array}$ & \\
\hline \multirow[t]{2}{*}{$\begin{array}{l}\text { for projects } \\
\text { targeting ... } \\
\text { innovation }\end{array}$} & $\begin{array}{c}\text { More } \\
\text { Innovative }\end{array}$ & $\begin{array}{l}\text { - } \quad \% \text { projects that met technical objectives } \\
\text { - } \% \text { projects that met market objectives } \\
\text { - } \% \text { projects on time } \\
\text { - } \% \text { projects on budget }\end{array}$ & $\begin{array}{l}65.92 \\
59.11 \\
46.89 \\
50.97\end{array}$ & $\begin{array}{l}26.62 \\
26.09 \\
26.51 \\
28.06\end{array}$ & \\
\hline & $\begin{array}{c}\text { Increment } \\
\text { al }\end{array}$ & $\begin{array}{l}\text { - } \quad \% \text { projects that met technical objectives } \\
\text { - } \quad \% \text { projects that met market objectives } \\
\text { - } \quad \% \text { projects on time } \\
\text { - } \quad \% \text { projects on budget }\end{array}$ & $\begin{array}{l}71.52 \\
67.41 \\
60.07 \\
63.72\end{array}$ & $\begin{array}{l}28.53 \\
27.55 \\
26.96 \\
28.64\end{array}$ & \\
\hline \multirow[t]{2}{*}{$\begin{array}{l}\text { SM Need } \\
\text { Information }\end{array}$} & 47 & \multicolumn{3}{|c|}{$\begin{array}{l}\text { How often do you use SM tools to gather information about your customers and } \\
\text { products in the front end? 5-point Likert scale with } 1=\text { never, } 5=\text { virtually always. }\end{array}$} & 2.39 \\
\hline & $\begin{array}{l}- \\
- \\
- \\
- \\
- \\
- \\
- \\
- \\
- \\
-\end{array}$ & $\begin{array}{ll}- & \text { Blogs } \\
- & \text { Wikis } \\
- & \text { Twitter } \\
- & \text { YouTube } \\
\text { - } & \text { Flikr/Photobucket } \\
- & \text { Monitor content distribution to other sites } \\
- & \text { External social network presence (e. g. Facebook) } \\
- & \text { Branded social network/community } \\
- & \text { Discussion forums } \\
- & \text { Innovation hubs } \\
- & \text { Ratings and Reviews }\end{array}$ & $\begin{array}{l}2.02 \\
1.76 \\
1.76 \\
1.93 \\
1.59 \\
1.98 \\
2.00 \\
2.06 \\
2.24 \\
1.91 \\
2.15\end{array}$ & $\begin{array}{l}1.13 \\
1.05 \\
1.02 \\
1.06 \\
.98 \\
1.09 \\
1.13 \\
1.09 \\
1.05 \\
1.05 \\
1.24\end{array}$ & \\
\hline
\end{tabular}

SM Solution Information
58 How often do you use SM tools to gather information technical information during 2.44 product development? 5-point Likert scale with $1=$ never, 5= virtually always.

$\begin{array}{ll}\text { - } & \text { Blogs } \\ \text { - } & \text { Wikis } \\ \text { - } & \text { Twitter } \\ \text { - } & \text { YouTube } \\ \text { - } & \text { Flikr/Photobucket } \\ \text { - } & \text { Monitor content distribution to other sites } \\ \text { - } & \text { External social network presence (e. g. Facebook) } \\ \text { - } & \text { Branded social network/community } \\ \text { - } & \text { Discussion forums } \\ \text { - Innovation hubs } \\ \text { - }\end{array}$

Formalization 25 What most closely describes your Unit's NPD process?
(1) No standard approach to new product development

(2) While no formally documented process is followed, we follow a clearly understood path of the tasks to be completed in product development. (3) We have a formally documented process where one function completes a set of tasks, then passes the results on to the next function, which completes another set of tasks. (4) We have a formally documented process where a crossfunctional team completes a set of tasks; management reviews the results and gives the go-ahead for the team to complete the next set of cross-functional tasks.
Innovation Culture
$1 \quad$ Thinking about culture, what percent of time does your organization reflect these 1.24 values? 5-point Likert scale in which $1=$ never, $5=$ virtually always. 


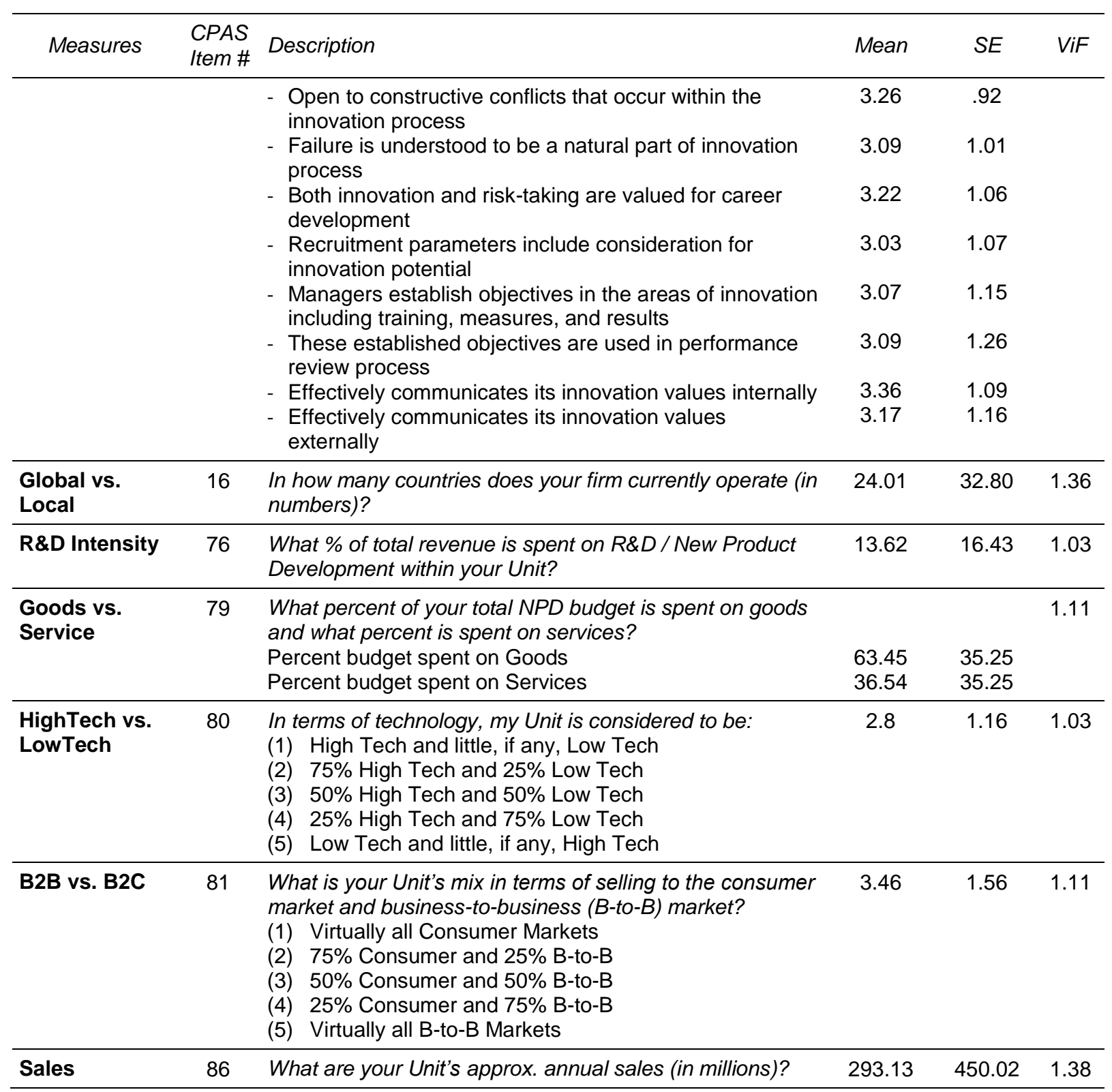


Appendix B: Plots of the Interaction Effects

< Add Figure B1a and B1b here > >

Figure B1: Interaction effect of SM usage and formalization for more innovative projects (only slopes (1) and (4) \& (2) and (4) are significant $(\mathrm{p}<0.005)$ and should therefore be allowed to interpret)

\section{<< Add Figure B2a and B2b here $>>$}

Figure B2: Interaction effect of SM usage and formalization for incremental projects (only slopes (1) and (4) \& (2) and (4) are significant ( $\mathrm{p}<0.005)$ and should therefore be allowed to interpret) 